\title{
UNIVERSITYOF
}

FORWARD

THINKING

WESTMINSTER用

WestminsterResearch

http://www.westminster.ac.uk/westminsterresearch

'Maiden, whom we never see' : cultural representations of the 'lady telephonist' in Britain, c.1880-1930, and institutional responses

Glew, Helen

This is a pre-copyedited version of an article accepted for publication in Information \& Culture: A Journal of History following peer review. The definitive publisherauthenticated version is available through the University of Texas Press at:

https://muse.jhu.edu/article/749004

The WestminsterResearch online digital archive at the University of Westminster aims to make the research output of the University available to a wider audience. Copyright and Moral Rights remain with the authors and/or copyright owners. 


\title{
'Maiden, whom we never see'1: cultural representations of the 'lady telephonist' in Britain, c.1880-1930, and institutional responses
}

\begin{abstract}
This article examines attitudes to the female telephone operator in the British press and a range of literary and cultural sources. Perceptions of female telephonists were rooted in both reactions to the increasingly visible employment of women in white-collar work and uncertain responses to the telephone as a new communication medium. Such perceptions of the female telephonist became stereotyped and static, though there were later some challenges to, and attempts to nuance, these. The General Post Office took over the service and implemented a number of changes, but ultimately the organisation and telephonists themselves had to co-exist with these stereotypes.
\end{abstract}

This article traces the emergence and solidification of the highly gendered and often negative discussions of the female telephonist in the public sphere in Britain. To do this it examines a wide range of press coverage, organisational records, and various literary and cultural sources from the late 1870 s to the early 1920 s to trace the largely static and repetitive nature of these perceptions and the ways they became tropes which were largely, but not exclusively, unchallenged. The article argues, in part, that the coincidence of women's employment as telephonists with gradually increasing telephone use meant that responses to women telephonists were filtered through the dual lenses of frustrations with still-unreliable technology and the wider cultural reaction to increased white-collar work for women. The article then examines the responses of the General Post Office (GPO), the employer of the vast majority of telephonists working at public telephone exchanges from 1912, which had to grapple with the effect of the dominant perceptions of telephonists on its workforce and recruiting. Whilst important work has been carried out by Michele Martin and Jill Galvan on the figure of, and reactions to, the telephonist in Canada and primarily the United States respectively, and as Galvan notes, there was a certain internationalism to the way in which the telephonist was perceived, ${ }^{2}$ this article is the first scholarship to consider cultural understandings of the telephonist in Britain.

There is a growing literature on the history of telephone systems in Britain but much of this to date concentrates on the ownership, business and network side of the technology as a means to explore the idiosyncratic case of the adoption of the telephone in Britain. ${ }^{3}$ There is 
far less discussion of the workforces in telephone exchanges and their day-to-day experiences. This article thus contributes to several distinct bodies of historiography. In adding a new dimension to the historiography of telephony in Britain by discussing who telephonists were and reactions to them, it also builds on the aforementioned existing work on the North American context, thus adding further to the transnational history of cultural understandings of women and telephony. In particular, the article demonstrates that whilst there were specifically British reactions to the emergence of the female telephonist determined in part by the idiosyncratic way the technology took hold in the country, British cultural understandings of the telephonist were also affected in part by increasingly transatlantic newspaper coverage and a telephone service which adopted ideas from the USA about how to improve.

Furthermore, this article also seeks to insert the female telephone operator into the literature on perceptions of young, lower-middle and largely white, largely urban, women workers in late nineteenth century Britain. Indeed, like elsewhere in Europe and the Anglophone world, the final decades of the nineteenth century saw the definitive emergence of women as whitecollar workers in Britain. Historians have explored the ways in which this change was both gradually negotiated and contested, and also the ways in which women clerks, typists and telegraphists, amongst others, were perceived. ${ }^{4}$ Anxieties and conversations about gender in the late nineteenth century generally coalesced around young women in urban spaces. This was in significant part due to the 'woman question' originating in the sex imbalance in the population and the recognition that it was therefore impossible, numerically, for a considerable number of women to marry. The young, independent woman was becoming an increasingly common feature of British cities as she lived away from home, earned an income and was becoming markedly more visible on the streets and workplaces. ${ }^{5}$ Thus the increasing presence of urban, white-collar women workers, alongside the more upper-middle class 'New Woman' of the 1890s, led to increasing concerns about the future of carefully-segmented gender roles and of marriage, and therefore of middle-class society and propriety as a whole. ${ }^{6}$ This context is significant in terms of understanding elements of the reception of the telephonist, though as yet the telephonist is not discussed in any depth in the literature.

These anxieties about women workers co-existed with the discourse that women were secondary workers: because of patriarchal, cultural and medical assumptions, they were relegated to less important, more routine and more repetitive work which was portrayed as being particularly suitable for them because of their gender. ${ }^{7}$ Owing to both formal marriage 
bars and endemic social expectations that middle, lower-middle and some working-class women would leave work on marriage, women workers were also seen as temporary, less worthy of more complicated or advanced (and therefore better-paid) work and as permanently on the marriage market, which undoubtedly also enhanced stereotypes of women in telephone exchanges and other workplaces as flirtatious, potentially seductive and looking for a mate. ${ }^{8}$

The article begins by discussing the process of feminisation of the telephone operator staff in Britain and some of the overarching conditions of their work, before considering the position of the operator relative to interaction with, and user experience of, telephone technology. The article then demonstrates the emergence of certain recurring tropes about the telephonist in the press before offering a case study of press and public responses to the introduction of standardised phrases by GPO exchanges in 1908, which demonstrates the density and layering of often negative and sometimes competing understandings of the female telephonist. These responses also gesture to the fact that some commentators realised the damaging and unhelpful nature of typical depictions of telephonists and recognised the impact these might have on women workers. Fictional depictions of the telephonist are then considered in order to examine the ways in which stereotypes of the telephonist had become so ubiquitous they could function both as plot points and as cultural motifs and metaphors. Finally, the article suggests that although time and changes to technology might gradually have lessened these depictions, they were too intractable to diminish quickly.

\section{The feminisation of telephone operation in Britain}

As the historiography elaborates, the telephone in Britain had an unusual history in terms of its operation and control. What started out as private enterprise was then partially taken over by the General Post Office (GPO), who then licensed private companies to operate telephone services whilst eventually also setting up GPO services in competition. Once the GPO exercised its right to not renew the licenses of private telephone companies, the telephone service ended up almost entirely in public ownership by $1912 .{ }^{9}$ Private companies initially employed boys on the work from the late 1870s but after a few years it appears to have been decided that they were unsuitable for the work. Significantly, despite this apparent judgement by employers, few complaints about the inefficiency or unsuitability of boys appear to have made it into the press of the very late 1870 s and early 1880 s, though the fact that there were so few telephone subscribers at this point may be a factor here. There are few existent records 
from the private telephone companies to document the decision to move from employing boys to employing girls and young women but it seems that various contemporaneous notions of femininity were used to justify the idea that women would be the better employees: they were more likely than boys to be polite, to be able to sit still, and to be able to attend properly to the dexterous and precise work of operating a switchboard. ${ }^{10}$ The decision a few years previously to employ women instead of boys on telegraphy might also have been influential: although telephony was different to telegraphy in a number of ways, both required significant manual dexterity, patience and attention to detail and if an argument was made for nimble fingers and the 'delicacy of touch' women apparently possessed being useful for telegraphy and typing, a similar sort of argument could be made for employing women as telephonists. ${ }^{11}$

Significantly, too, these justifications about gender characteristics provided a convenient mask, as numerous other scholars note, for the fact that current social attitudes and employer policies meant that the telephone companies, and later the GPO, could pay women less than men for what would manifestly be the same work. ${ }^{12}$

Thus, the position of telephonist in Britain was gendered female almost from the beginning of its existence. This had significant and increasingly magnified cultural and social implications. Whilst the act of verbal communication via telephone remained often the province of men in a professional context, women were agents of this new, modern, and sometimes anxietyinducing method of communication and were also closely aligned with the technological difficulties and annoyances it brought. The novelty and anxiety of this new technology clearly coexisted with the novelty and fears about the swift emergence of an entirely new employment for women and for more than two generations these anxieties remained intertwined. Significantly, it is argued that many reactions to women telephonists were harsher than those to, for example, women telegraphists and typists, largely due to the active role the telephonist had to play in calls, the authority she was thus seen to be claiming, and the impatience of subscribers. ${ }^{13}$

\section{Bodies and Voices}

With the telephone came the transmission of disembodied voices (even if these voices were sometimes familiar) and this was arguably doubly new and unusual because the voices included those of the female telephone operator. Although women's white-collar employment was becoming increasingly prominent as we have seen, the professional and business worlds 
were largely still understood as male domains and men as authority figures. The areas in which women were consistently heard in public were the stage - with all of the risqué implications that this carried with it - and, by the early twentieth century, the various public spaces and platforms of the suffrage movement with all of its (initial) connotations of deviance and rebellion. Thus, women were now audibly and publicly assisting business and professional worlds and the women who worked as telephonists at GPO exchanges had, effectively, their voices sanctioned by the state, and were sanctioned to be the official voices of the GPO, just as those who worked at Post Office counters were, as Patrick Joyce has noted, the arm of the state in the community. ${ }^{14}$ There were specific criteria about these voices, too: whilst female telephonists were usually recruited from a lower social class than both women clerks, who were required to have a higher level of education, and women telegraphists, both the national telephone companies and the GPO had quite strict criteria about women having good diction and clear, accent-less voices. This was, of course, coded language about the women sounding appropriately middle-class with neutral (London/home counties) accents. ${ }^{15}$ This had significant implications for applicants to, for example, the London Telephone Service (LTS), which required a vastly greater number of workers than many other areas. In the late 1920s a furore over a seeming denial of an interview to a Welsh applicant revealed the ways in which the GPO was less keen on employing women from Wales, Ireland and Scotland in London because of the potential strength of their accents. It seemed to many onlookers that in the capital's telephone system, accents from England (and in particular southern England) were preferred to those from any of the other three nations making up the United Kingdom. ${ }^{16}$

The work of a telephonist was simultaneously skilled, stressful, repetitive and interchangeable with that of colleagues. As women made up the cohort of daytime employees, and daytimes were when the majority of phone calls were made, their working days were manifestly more stressful than night shifts were for male telephonists. The nature of the exchanges, with their wires and switches to make physical connections, meant that the work often had to take place in cramped conditions and in close proximity with colleagues. Christopher Keep, Pamela Thurschwell, Jill Galvan and Katherine Mullin, amongst others, have discussed the ways in which female telegraphists and typists were understood to embody aspects of their work by using their minds and fingers to mediate, transcribe and facilitate communication. ${ }^{17}$ Not only was the telephonist's hearing and voice a medium for facilitating the call, her body was essential to making the connection. The rule about 
minimum height (five feet three inches under the National Telephone Company, reduced to five feet by the GPO in 1902) existed so that the telephonist would be able to reach all of the 'switches' on the switchboard so that she could insert the pegs to connect the call. ${ }^{18}$ When Drs Minnie Madgshon, John Sinclair and A Wilson, medical officers in the GPO, submitted their report on the working conditions of telephonists in 1910, they wrote of the "perpetual jumping up and down and reaching required, especially in junction working, which tend to cause physical weariness.' 19

The bodies and voices employed were largely those of white women. Although there are no existent staff records from the private companies, it is clear from the transition arrangements made between the National Telephone Company (which had, by the 1890s, taken over several smaller private companies) and the GPO that the vast majority of women employed were likely to have been white and with English as a first language. On application to transfer staff, the Treasury refused the requisite paperwork to several members of staff who were 'aliens' and who had not attained certificates of naturalisation. ${ }^{20}$ Furthermore, Civil Service requirements stated that employees needed to be 'natural-born' British subjects and have fathers who were the same. Whilst this technically allowed employment to women who were citizens of the British Empire, as Venus Green has shown the power of whiteness in the GPO and wider Civil Service was such that even by the 1950s, when citizens of British colonies had been granted full citizenship rights, there were even then very few employees of colour due to discrimination by interviewers and endeavours to find other convenient excuses or technicalities not to employ people of colour. ${ }^{21}$ That said, in spite of discriminatory attitudes, in 1912 Audrey E Gaines was appointed to the LTS. Although the surviving records do not fully delineate her ethnicity, it is clear that she was a woman of colour. The LTS later reported having to move her from supervisory duties to other work entirely because her white female colleagues resented taking directions from her. The fact that this issue was described with specific reference to her suggests that she may have been the sole employee of colour in the telephone service. ${ }^{22}$

With the takeover by the GPO in 1912, National Telephone Company employees also became subject to a range of other rules, but also some benefits. The age of beginning the work became more restricted than it likely had been under the private companies: the age range for GPO telephonists did vary slightly over time, as we will see later, but with the takeover, the age range for admission was generally 16-18 years old. This therefore further 
cemented the idea that female telephonists were young - with all of the connotations about flightiness, irresponsibility, impressionability and frivolity that could come attached to this. ${ }^{23}$

Women civil servants were subject to a strict marriage bar. ${ }^{24}$ There was some embarrassment amongst the GPO hierarchy during the takeover process when it realised it had omitted to mention this in staff briefings about the takeover; special exemptions had to be arranged for the handful of married women who worked as part-time telephonists. ${ }^{25}$ Once women civil servants had passed the relevant qualifying exam, and the efficiency test after a few months' service, they were guaranteed a job for life (unless they married) with a non-contributory pension. Although telephonists were towards the bottom of the Civil Service hierarchy, the job was more secure than equivalent white-collar work in private businesses and perhaps carried a little more cache because of the holder's status as a civil servant. However, because the job - in the daytime at least - had become so demarcated as female and thus had been sidelined as 'women's work', the horizontal segregation meant there were relatively few opportunities for career progression. It is probable that the GPO offered more than the private companies thanks to possible avenues of promotion into Civil Service clerical work, but the lack of existing records for the private telephone companies makes this supposition difficult to confirm. ${ }^{26}$

\section{Anxieties and the telephone as new technology}

Whilst some potential and actual users were excited by the prospect of the telephone, its business possibilities and convenience, there was also resistance to the adoption of the technology, as Michael Kay in particular has shown. ${ }^{27}$ The telephone furthermore raised new issues about interruptions into one's daily life. Whereas frequent mail deliveries and telegrams were interruptions of a sort, they were essentially one-sided, asynchronous communications unless the recipient decided there and then that a reply was necessary. The telephone, however, was different: its very essence was two-way communication which needed an immediate response and was therefore a more significant intrusion into daily life than other communication technologies had hitherto brought.

The late nineteenth century with its development of the telegraph, typewriter and telephone also became the site of concerns about information management and information overload. The speed with which information could now be copied, shared and even generated (for example, via the production of reports, policy documents, print journalism and novels) 
instilled anxieties about 'keeping up' and 'staying informed' and the pace of life. ${ }^{28}$ The telephone, arguably, took these elements one step further. Telephonic communication meant that nothing necessarily had to be written down - unless the recipient of the call chose to make notes during the call, for example - and this introduced a greater element of instability to communication. Speech, travelling down a telephone line, was free-floating, and the telephonist could, in theory, listen in. Indeed, with some of the early systems the only way for a telephonist to know for sure that a call was over was to listen in periodically, and in the 1890s, call-wire technology meant that the telephonist was permanently connected to the lines on her particular switchboard and listened for subscribers requesting connections. ${ }^{29}$ Even when telephone technology advanced, the telephonist had to listen to the first three seconds of calls to make sure the connection had been made properly and also had to interrupt the conversation to ask subscribers if they wanted more time when three minutes' call time had elapsed. ${ }^{30}$ The discomfort that subscribers clearly felt about the possibilities of telephonists listening in is reflected in numerous of the fictional depictions of telephonists in the early twentieth century, as we shall see later. This fear of telephonists listening in is particularly striking when it is compared to discussions of typists who also had the means to access and share confidential information. However, the fear of telephonists discovering private information appears to have been stronger: typists, instead, were often positioned as neutral automatons who typed their copy without actually processing the meaning of their words. ${ }^{31}$ Similarly, while telegraphists would come across urgent or sensitive information in the course of their work, crucially, they had access to only one half of the information and not the whole conversation.

Furthermore, the telephonist remained largely anonymous. As the caller could only hear her, he or she had no visual clues as to the propriety, professionalism or social acceptability of the telephonist such as would be available in a telegraph office, Post Office setting or other business environment. Whilst the telephone was, on the one hand, a means to share information without having to commit it to paper and thus risk the information falling into the wrong hands, it was also, as Patrick Joyce has noted, never a totally private means of communication because it involved using operators as a conduit ${ }^{32}$ and the thought of a young woman potentially listening in increased anxiety for some subscribers. Furthermore, in more rural areas or small towns, where the telephone exchange was necessarily of a much smaller scale, it was of course perfectly possible that the telephonist and the two callers would know each other, which created its own specific concerns around privacy, discretion and 
knowledge. As Brenda Maddox has noted for the US context, the rural telephonist 'had social status as well as genuine power in her community, knowing as she did the whereabouts of the doctor, the fire chief, and the contents of most people's telephone calls. '33 The telephone was revolutionary and opened up myriad possibilities for businesses, institutions and the wealthier households which initially used it, and in the early years of the telephone users had no choice but to interact with a telephonist. This was significant: not only was the telephonist often a stranger, she was also integral to the success of the communication method. She was of a higher social class than the domestic servants employed by subscribers, but subscribers had to negotiate the fact that they could not quite order the telephonist around in the way that they might a domestic servant. Although she was meant to do what the subscriber asked in relation to connecting telephone calls, her position and control of the switchboard also meant that she retained power, and the potential choice not to be helpful. ${ }^{34}$

\section{Portraying telephonists in the press}

The image of female telephonists as flighty, ditsy, inefficient and gossipy emerged quickly. It is important to note how gendered these depictions were: when operators were male, the position of the operator was discussed relatively neutrally, with the inference that they were trained well enough to perform what was required of them. ${ }^{35}$ By contrast, female operators were remarked on specifically as women - such was the novelty of their presence - and imbued with largely negative traits that were stereotypically deemed to be feminine. Once women were employed the press made comment on their voices, their perceived capabilities, and their physical appearance when reporters toured exchanges. ${ }^{36}$ This was surely part of a wider commentary on the novelty and growing prominence on women in white collar work but had the net effect, as the number of telephone subscribers grew, of women telephonists also becoming synonymous with the service and its failings.

In July 1881 the Hull Packet and East Riding Times argued that '[i]t is a noteworthy fact that women make the best operators for telephone exchanges. There is so much talking to be done that they feel comparatively happy, and then they hear something not intended for their ears, which is blissful. ${ }^{37}$ Despite intending to be humorous, the underlying assumptions on which the joke was predicated were clear. This assertion built on the stereotypes that women were chatty and also enjoyed gossip and learning secrets, and there was a certain level of infantilisation in the assumption that women needed to be kept entertained at work. 
Similarly, in one of its on-going series of gossip and jokey musings The Hampshire Advertiser in 1898 printed a fictitious exchange between two men in which they concluded that women were so often telephone operators 'because the occupation puts them in a position to have the last word every time.' ${ }^{38}$ Such supposedly amusing discussions were rooted in crude stereotypes and were a constant in media portrayals of telephonists, which certainly hinted at a discomfort that women were so prominent in this work and had become so so quickly. In 1901 the Daily Mail attempted a scientific explanation to manufacture a post-hoc justification of the female daytime telephone workforce: women made better telephone operators, they argued, because they had shorter vocal cords and their voices carried better across the equipment. Notably, the reporter named no specific scientific research or principles. However, just in case this was not considered justification enough to explain their presence, the writer also pointed out that women had better diction than men, 'will use a larger percentage of the short, crisp, homely Anglo-Saxon words and show an avoidance of abstract Latin-derived words' - an observation which might be read as a backhanded comment on women's lesser education - and would hold up better to the nervous strain of telephone work. ${ }^{39}$ The reasons for women's employment just so happened to back up the status quo and even went so far as to suggest that women coped better with nervous strain when nearly all other such discussions of women and mental stamina argued the exact opposite.

Another facet of the depiction of women as telephonists was the claim that they were inefficient and deliberately hung up on subscribers. Any problems with the technological aspects of the system were automatically blamed on the female telephone operators: as they were at the forefront of the technology, subscribers' wrath was directed to them. In 1898 The Pall Mall Gazette recounted the GPO's costs for the preceding year and generally complained about the service. The final image it left readers with was that there were now ' 110 more lady telephonists ready to cut you off this year than there were last.' ${ }^{40}$ Such was the ubiquity of this element of the representation of the telephonist that every so often various newspapers went to interview telephonists and to tour exchanges so that they could then bring to readers an authentic account of the telephonists' working day. Without fail in each interview, a telephonist would explain the complexity of the exchange, the pressures, and the fact that incoming calls were dealt with separately to outgoing ones so the subscriber who called to complain that the last call he received was inaudible was inevitably shouting at the wrong person. These periodic interviews were thus attempts to counter stereotypes but they 
became such a genre in themselves that they may have added inadvertently to the tropes or given the sense that telephonists were trying too hard to defend themselves. ${ }^{41}$

What is particularly striking is how quickly these perceptions emerged and were solidified relative to the emergence of women as telephonists and Britain's slower adoption of the telephone compared to other nations because of the specifics of the system and its costs. ${ }^{42}$ Furthermore, until after the First World War, the telephone was largely used for business communication and the majority of users were middle and upper-middle class men in a specific subset of occupations, which meant that the perceptions were shaped by a fairly narrow set of users. These included, of course, the press, which boosted its role in creating and perpetuating these stereotypes. Another significant factor was that the same kinds of portrayals of the female telephonist emerged in the United States and some of these were also reported as snippets of international news in the British press, presumably precisely because it was thought they would be interesting to, or resonate with, readers in Britain. ${ }^{43}$ The compounding effect of this reporting was highlighted by a telephonist herself, who told a Manchester Guardian reporter who interviewed her in 1886 that the issue with British papers taking coverage from their American counterparts was that the public absorbed the continual disparagement of the US telephonist and then applied these depictions to female telephone operators in Britain. ${ }^{44}$

In 1890 this transatlantic news coverage extended to the reprinting in more than one British paper of the story of two telephone exchange officers, one in South Bend, Indiana, and one in Michigan, who had wiled away the long overnight hours by talking to each other on the phone. The man proposed marriage to the woman and so the couple exchanged wedding vows with each other over the telephone, adding a Justice of the Peace to the call. A judge later ruled that despite the couple not obtaining a licence, the marriage was legally binding. Several US papers reported that the groom was now visiting South Bend to meet his new wife and that a divorce might be instigated if the pair did not strike up an amicable relationship in person. ${ }^{45}$ Some weeks later the news broke that he had, in fact, also been engaged to another woman. ${ }^{46}$ The US papers then dropped the story so it is not clear what happened to the couple. However, the changes made in the reporting of the story to British audiences were significant and highlighted some of the anxieties underlying women having agency at the end of the telephone. The North Eastern Daily Gazette told its readers that the woman had turned out to be ugly and lame, knowledge surely impossible for it to have attained especially when in the US reports she was portrayed as pretty. ${ }^{47}$ She was apparently, according to this British 
report, pleased to learn that their marriage was legally binding and informed her new husband, by telephone of course, that she would be moving into his home. ${ }^{48}$ The story as told in the British press was illustrative of many of the ways in which the telephonist was perceived as a problematic figure and symptomatic of modern anxieties about technology, whilst simultaneously embodying some of the most potentially problematic traits of femininity. The British coverage offered the further implication that the telephonist had deceived him - she might sound like a young, pretty girl one can flirt with but she deviates from this preferred image of femininity through her ugliness and her lame-ness. Finally, she has 'ensnared' the male operator and will now apparently be entering his life in person.

Notably, too, whereas the US coverage tended to imply that both of the couple had been more or less equally foolish, the British press, by giving the woman the agency and embellishing details of her appearance, strongly suggested that the man was the innocent, hapless victim in the situation. Whilst this story was presented in the British press as whimsical, fun and something for which readers could feel schadenfreude, it fits into the trope of 'unfortunate things that can happen to unsuspecting men at the hands of women', revealing the extent of the cultural anxieties that the telephonist could create.

\section{Standardising voices and expressions}

Jill Galvan has argued that 'women were exemplary go-betweens because they potentially combined the right kind of presence with the right kind of absence. ${ }^{49}$ However, the GPO clearly felt that its women telephonists were too present, or certainly making themselves too noticed. In December 1908, inspired by the American Telephone and Telegraph Company, it issued instructions and set of standard phrases for telephonists so that 'abrupt and uncouth expressions may be avoided in the telephone service'. ${ }^{50}$ These included phrases such as 'Number, please?', 'Please repeat' and 'Your time is up. Will you have another three minutes?' as well as expressions covering eventualities such as when a call could not be connected, the dialling of a wrong number, or a customer enquiring to try to find a number. ${ }^{51}$ This was clearly partly in response to public feedback, and notably referred to the telephonist as 'she' throughout, so thoroughly was the identity of telephonist a female one. The expressions ultimately functioned as a means to simplify and standardise processes, but interestingly, by controlling what the telephonist could and could not say, they also seemed to ally with rhetoric that saw the telephonist as an automaton who therefore did not have human 
foibles and frailties such as varied phraseology or more emotional reactions to customers, and the process of telephony as one that could be entirely automated. ${ }^{52}$ Clearly, of course, the adoption of standardised expressions therefore effectively policed telephonists' speech and interactions with the public. As the Birmingham Evening Despatch reported, 'the manual can scarcely be called complete, because there are no rules included for the users, and thus the obligation is one-sided, constituting a tacit acknowledgement of the privilege of a user to say what he likes to an operator, but drastically restricting the language of the operator to the user.' The reporter therefore gleefully pondered the ways in which the words 'please' and 'thank you' might be sarcastically or angrily delivered when a telephonist was dealing with an irate subscriber. ${ }^{53}$ Indeed, as this reporter implicitly suggested, the standard phraseology left the telephonist with very few ways to de-escalate a situation, beyond passing the call to a supervisor, if a subscriber became angry, demanding or abusive.

The range of reactions from the press, the public and telephonists themselves to these phrases was significant. Much of the commentary reflected and enhanced the existing negative portrayals of female telephone operators but some of the reactions demonstrated sympathy for, or a kind of affiliation with, the female telephonist, suggesting that some commentators were willing to challenge the dominant views. Undoubtedly, the new instructions got more coverage because they were issued by a public body, ever the targets of ridicule and irreverence. Some newspapers picked up on the fact that the Post Office was issuing these instructions in an attempt to ingratiate themselves and to be a moral force, the Dundee Courier suggesting, for example, that the 'millennium [might be] actually at hand' now that the Post Office was combining business etiquette with being the 'inculcator of morals'. It was wryly remarked that this would escalate to the public not having to pay for calls unless they were impressed with how the call had been handled, and postmen giving away free stamps when they delivered letters. ${ }^{54}$

Other newspapers reacted in a way which revealed their disdain for women telephonists and reinforced existing negative perceptions. The Birmingham Daily Mail, for example, remarked that

'At last the General Post Office has awakened to the fact that it may be possible, and perhaps advisable, for telephone girls to improve themselves in the matter of courtesy towards clients. ...Instead of high-pitched, querulous, staccato grumbles we shall 
have our ears tickled by the sound of a sweet, musical voice apologising for a mistake or delay. ${ }^{55}$

The Manchester Despatch sarcastically remarked that it was useful that the Post Office had publicly announced these changes because subscribers would otherwise be too shocked when they made their next phone call. The Evening Standard was actively hostile, stating that 'we think too highly of the considered and determined rudeness of this peculiar class of public servants to believe that a little thing like that will have any power to turn them, vanquished, from their enterprise of insolence. ${ }^{56}$

Several newspapers interviewed telephonists about the guidelines. In Manchester, telephonists were quick to point out that subscribers also needed an etiquette guide, and that at busy exchanges, a telephonist might deal with 1,600 calls per eight hour shift. One commented that telephonists were too busy to be rude to subscribers, and that though she admitted that less experienced women might be more short-tempered, “ "I sometimes wonder if men would be as sweet-tempered as the average "phone girl under similar conditions." ‘ 57

Responses were gendered also in the form they took. The Daily Chronicle carried a poem dedicated 'To the Invisible "She", the 'Maiden, whom we never see' who would teach subscribers politeness. ${ }^{58}$ In a similar vein, the Daily Mail printed a twenty-four line poem on the theme that instructions for telephonists might also create more polite subscribers which ended with the couplet 'Yea, here I beg it on my bended knees/Give me, sweet maid, six thousand Holborn, please!' ${ }^{59}$ These responses were both mocking and espoused a performative sense of chivalry. The writer of the article in the Sketch proposed to the Postmaster General that any woman found not following the script should be mentioned by name in the Post Office Circular in order to shame her and other female telephonists into compliance. He argued that he and many other young men put off sending letters or telegrams because they were worried they might receive a stern response or a rebuke from the woman working behind the counter. The public naming of errant telephonists would, the writer argued, benefit nervous young men and Post Office revenue. ${ }^{60}$ Exaggerated or not, the appearance of this argument in print reveals the cultural acceptability of the idea that women telephonists should be made to serve a male agenda and be compliant.

The Irish Times noted that now that telephonists were required to ask callers if they wanted another three minutes, '[h]ow will any chivalrous man be able to refuse an invitation so insistent, and not without a soupçon of flattery?', which was a clear comment on age, gender 
and the suppositions projected onto the telephonist. ${ }^{61}$ Other newspapers noticed the sales dynamic in this new practice and satirised the fact that a state body was behaving like any other private business. ${ }^{62}$

Significantly, the new expressions were not universally popular with telephonists, several of whom wrote to their local Postmasters pointing out that the new expressions risked upsetting customers further and putting additional pressure on staff because of the length of time they took up. ${ }^{63}$ Responses recorded from the public also suggest that some subscribers, perhaps encouraged by the mocking and whimsical press coverage, were unimpressed by the new standardised expressions and tried to rile up telephonists when they used them. ${ }^{64}$

The new phrases of course did very little to alter the romanticisation of women telephone operators by some subscribers, as a Daily Mail reporter's thoughts revealed some years later:

'An unseen telephonist who occasionally answers my impatient calls has this same quality of sunshine in her voice.... When she says 'Number, please?' she makes a surly reply impossible. And when, as sometimes happens, she gives me the wrong number, she apologises so charmingly that it is I who regret the trouble I cause her.

'I shall never see her, but I like to imagine that her hair is as golden as her voice... and that she really is as happy as she sounds....

'Their happy influence comes, I think, from deep within them. It has nothing to do with the beauty that is but skin-deep. Its secret is an unquenchable optimism that springs from a generous soul in a healthy, well-poised body.' 65

From the telephonist's voice alone, the reporter projected the 'healthy, well-poised body' thus imbuing her physical appearance with certain attributes - and from there also made predictions about her soul, creating an ideal of the supremely calm, happy, contented woman and worker. Such perceptions served to make the (male) public feel better about the strains telephonists were under and to keep women preserved as idealised, romanticised objects.

\section{The telephonist in fiction}

Fictional accounts of telephonists in the early twentieth century deployed certain elements of the trope of the telephonist over and over again and so bolstered it, though at times fiction also offered space for some of the more sympathetic reflections on the telephonist. An 1897 American musical The Telephone Girl, based on a French production, featured a telephonist 
who overhears something and calamity ensues when she acts on what she hears. This, too, made it to British theatres, where critics pointed both to the predictability of the plot and the numbers of telephonists who went in parties to see it. ${ }^{66}$ Such depictions, which used the telephonist listening in as a plot point, emphasise the cultural anxieties around the telephonist in this sense, which in turn were wrapped up in gendered notions of women as gossips. Thus, although Jill Galvan has asserted that female mediums, such as telephonists, were seen to allay concerns about privacy, the evidence from British discourse and culture at the turn of the century seems to complicate or even reverse this picture. ${ }^{67}$

Richard Menke has argued that due to the slower adoption of the telephone in daily life in Britain compared to elsewhere, the telephone is less of a feature in late nineteenth-century British fiction. ${ }^{68}$ However, by the early twentieth century, telephonists were beginning to feature in novels, either as minor characters or cameos or more fully. In E. F. Benson's 1914 novel Dodo's Daughter, Dodo is fascinated by the workings of the telephone and the lives of telephonists. Early in the novel she tells her friend Jack that she has had three telephones installed in her London home, all while forgetting that she 'hadn't three ears'. She continues:

I really ought to have been one of the people in the Central Exchange, who give you the wrong number. You must feel really in the swim, if you are the go-between of everybody who wants to talk to everybody else; but I should want to talk to them all. ${ }^{69}$

Whilst perpetuating the stereotypes of telephonist incompetence, this also portrayed the telephone operator as at the centre of myriad conversational webs and connections, and conveys both a sense of the stress and pressure of the work as well as the paradoxical nature of the telephonist being at the centre of a conversational web whilst not being able to have a meaningful conversation with anyone. Elsewhere in the novel we see Dodo trying to make phone calls to friends, trying not to be rude to the telephonist and insisting on calling her 'Miss' in order that the telephonists are more polite. ${ }^{70}$ This served to perpetuate some of the wider stereotypes about telephonists' treatment of subscribers. Dodo also advocates the telephone over face-to-face conversation, telling her friend that 'I would talk to you for hours, simply to thwart the 'please, miss' who asks if we haven't done yet. ${ }^{71}$

Other fiction uses the telephone exchange, or sometimes the telephonist, as a metaphor, revealing the ways in which both the telephone system and the women who largely operated it had become recognisable motifs. In Virginia Woolf's Night and Day, Mary Datchet's coworker in the suffrage movement advises her that: 
'We must try to consider ourselves in the light of a telephone exchange -- for the exchange of ideas, Miss Datchet. ...We should consider ourselves the centre of an enormous system of wires, connecting us up with every district in the country. We must have our fingers upon the pulse of the community; we want to know what people all over England are thinking; we want to put them in the way of thinking rightly. ${ }^{172}$

Although the telephonist is not mentioned specifically as a figure, it is clear who is at the centre of the exchange, and whose fingers might, by implication, be on the pulse of the community, thus hinting at the enabling qualities of the telephonist and the benevolent way she can direct communication. This passage is particularly significant in a novel in which we otherwise see characters experience significant anxieties about writing, the fixity of the written word and the impossibility of verbalising particular feelings. ${ }^{73}$

One British depiction which portrayed the telephonist sympathetically and as a serious worker, and thus attempted to rethink some of the dominant perceptions, was the 1918 novel by the married couple fiction-writing team of Claude and Alice Askew. The Telephone Girl is, in many ways, an awkward novel and was clearly written for the popular sensation-fiction market. However, the level of discussion of the specifics of work as a telephone operator is striking, suggesting research and a real interest in trying to get the details correct. As an orphan who managed to achieve an education sufficient to qualify her for the work, being a telephonist is the most important facet of Peggy Ryley's sense of self. This is contrasted with the derision with which her suitor's family, who are practically the aristocracy, greet her work.

The novel opens with Mrs Jackson, who raised Peggy from a baby in her boarding house, on her deathbed. She reveals to Peggy a secret she has kept since Peggy was born: rather than being an orphan of destitute parents, Peggy is, in fact, the daughter of a titled nobleman and she has documentation from Peggy's late mother to prove it. However, despite Peggy's elation at the initial discovery, the documentation is stolen by two of the novel's villains, unbeknownst to her. Thus, as the novel goes on, Peggy ceases to believe Mrs Jackson's story and puts it down to the delirium brought on by sickness. It essentially remains for Peggy to continue her job as a telephone girl, which she likes and which promises her a level of income and a normality that she has not really had previously, and to decide what to do about her relationship with her suitor Owen Hughes and his sneering relatives. 
In a novel full of coincidences, awkward exposition and plots and subplots between and against characters, it is of course her work as a telephonist which allows her to determine one piece of the puzzle of her life: although she has said yes to him, she does not want to marry Standish Grome, who has in fact been instructed to bait her into marriage by Owen's mother. As she admits, she happened to deal with a call at the exchange between her new fiancé and one of his associates and she discovers his true character:

I didn't want to listen, but I couldn't help hearing a few words: they were enough to make me listen to more, in defiance of all the regulations. It was my whole future that was at stake, you see. I needn't tell you what I heard. Mr Grome was condemned out of his own lips. ${ }^{74}$

She is aware that she has broken the rules as a telephonist but in the context of the novel this is thoroughly excused because it allows the heroine to save herself. That the authors are playing with the trope of the telephonist as detective/spy/saviour of the day is abundantly clear when Standish Grome's reaction to the situation is revealed and we enter his interior monologue:

'[T]hen, throwing off any further effort at deception, he relieved his mind by cursing the telephone system, his man Wheeler, and even Peggy herself, for having played what he called the spy.' 75

Other elements of the cultural understandings attached to telephonists may also be at work here. In her study of the concomitant rise of women in telegraphy and telephony and the increase of female spiritual mediums at the end of the nineteenth century, Jill Galvan notes that women in these roles were, to various degrees, imbued with a sense of sympathy, telepathy and connectedness with others and were perceived as making 'at-a-distance' communication less psychologically difficult by acting in the professional role of intermediary. ${ }^{76}$ In the novel, the character who saves the day more than any other is Lord Caversham, Owen's uncle, who eventually decides to go and investigate the situation further with a view to meeting Peggy after he reads a letter she sends Owen explaining why she has to break off their engagement:

'Lord Caversham...had read into the heart of Peggy without ever having seen her, and this from a few written words only. Perhaps - who can say? - some mysterious sense of affinity was aroused within him... 
' $[\ldots]$

He imagined that he heard the voice of Peggy calling him, and it was a voice that thrilled him through and through - there was something in the intonation of it that touched a sensitive chord in the very depth of his being.' ${ }^{77}$

Notably, this is another trope of depictions of the telephonist as we have seen: the power of the voice. In this case, Peggy's power to communicate goes beyond the realm of the everyday. As Caversham tells Owen, '[f]rom the first moment you spoke to me of Peggy, I felt there was something. I couldn't define it; but she was always seeming to draw me to her.' 78

The supernatural, was, of course, a common trope of popular fiction - not least because it was useful as the last-resort plot device. But in this case, Peggy is also serving as both the technological and communicative medium but also, at least in Caversham's eyes, the medium with the power to transfer thoughts and feelings between two human beings without them even knowing each other. (This is saved from being an awkward and potentially predatory portrayal of communication between two strangers because Caversham is in fact Peggy's long-lost father, something which the reader knows from much earlier in the novel but Peggy does not.) Peggy thus represents both facets of Galvan's 'sympathetic medium'. As Galvan argues, we can see 'women's operating, typing, and séance channelling not as separate functions but as different expressions of the same one.'79

\section{Co-existing with the depictions: recruitment and employment of telephonists by the GPO}

By the time the GPO began taking over the telephone systems in the first decade of the twentieth century, the often negative and stereotyped perceptions of the telephonists were entrenched. The extremes of views of telephonists were perhaps best encapsulated by reactions to the possibility of automation. This did not in the end become the norm for local calls in Britain until the 1930s but was on the horizon much earlier. In 1898, the Weekly Standard and Express, based in Blackburn, Lancashire, mused on what such a change might mean and revealed the extent to which the 'telephone girl' had already become mythologised and an object of sentimentality and advance nostalgia, and that at least some of the public had learned to co-exist with her and her perceived foibles: 'if all that is claimed for an automatic telephone exchange is verified by actuality, the "engaged" girl is threatened with extinction', it said, playing with the idea of girls as romantic objects and telephone lines being already in 
use. The last line noted wistfully: 'She has become an institution, and many would be loth to part with her.' ${ }^{\prime 0}$ For this particular reporter, the fact that public discussion of the telephone girl had made her such a defined and recognisable figure now meant that her absence from daily life would be felt all the more keenly.

Some of the male-dominated sections of the Civil Service, by contrast, had few such sentimental views. In 1911, as the prospect of the first automatic local telephone exchange was on the horizon in Epsom, Surrey, the Civilian published a vitriolic article castigating women telephonists for apparently stealing men's jobs by accepting lower pay. ${ }^{81}$ This was a familiar cry amongst trade unions and male workers within the Civil Service and elsewhere. ${ }^{82}$ The writer gloated that '[i]f the use of automatons spells economy, not all the tears and protests of would-be telephone operators will prevent the closing of that outlet for their girlish activities. ... Time brings its own revenge, and girls who have undercut men and boys in the wages market will themselves be undercut by the sweatless industry of cheap machines.' 83 The infantilisation and resentment of these women workers was clear. However, as the Association of Post Office Women Clerks - who represented women workers on other GPO grades - pointed out, men had hardly been telephone operators in Britain due to the advocacy of the work for women from the beginning. ${ }^{84}$ However, it was precisely the gendering of this work as female that made it the target of such vitriol.

\section{The response of the GPO as an institution}

Just as the myriad and solidified depictions of the female telephonist borrowed from and layered upon one another, the GPO hierarchy's views of its own staff clearly did not exist in a vacuum. The central GPO hierarchy, dominated by white, upper-middle class and universityeducated men, of course shared many of society's dominant perceptions of young lowermiddle and middle-class women that were rooted in combined perceptions and prejudices about age, gender and class. This was also apparent when the Treasury - which controlled the Civil Service, and therefore the GPO, financially - continued to refuse to employ female telephonists partly on account of the 'very important' communications carried out within their exchange. Clearly some of the gendered notions of women as indiscreet and gossipy were also shared by Treasury officials. ${ }^{85}$

Concern about the welfare of the telephonist reached a sufficient height by 1910 that an inquiry into the working conditions was carried out by three medical professionals. It visited 
exchanges around the country, interviewed telephonists, and involved the doctors wearing the equipment and testing the furniture. The inquiry concluded that as long as women who were physically and mentally robust enough were employed, telephony was no more dangerous an occupation than other types of office work. However, it did express concerns about the pressure of the equipment on women's bodies, the seating and equipment provided for them and the fact that they could be badly treated by subscribers, all of which contributed to mental and physical strain not usually found in other kinds of work. ${ }^{86}$ On receipt of the report, the GPO recognised the need for some changes, and indeed the report was published with a covering address by Alexander King, the Secretary of the GPO, outlining the changes that would be brought into effect. However, it is clear from GPO internal discussions that not all agreed with the arguments of the report and the changes made erred on the side of the essential and minimal. ${ }^{87}$

By the end of the First World War, it was evident that impressions of working conditions and the wider cultural discussions of the telephonist were affecting recruitment, though no doubt the wider opportunities for women because of the war also had an impact on the numbers of recruits. The GPO spent some time discussing this, getting recommendations from the London County Council Central Advisory Committee on Juvenile Employment, for example, which helped to pinpoint some of specific working conditions which were least popular. ${ }^{88}$ The staff side of the LTS Whitley Committee (the employer-employee negotiation machinery in the Civil Service) suggested recruiting women telephonists by the same method as other civil servants to elevate the prestige of the telephonist and so that the public might begin to see the telephonist in the same light as they did other civil servants. ${ }^{89}$ For short periods the GPO also slightly lowered the age limit for recruits to try to widen the pool from which they could draw. ${ }^{90}$ However, it was clear too that the negative press coverage was influential on potential recruits. ${ }^{91}$ Telephonists were certainly all too aware of press and cultural discourses about their work. Numerous articles in The Telegraph and Telephone Journal, published monthly from 1914, made clear the extent to which telephonists had to coexist with, and work hard to realign, perceptions of themselves. ${ }^{92}$

Throughout the interwar years the periodic articles about the stressful nature of daytime telephony continued.$^{93}$ However, as telephone technology became more reliable, there was certainly less new criticism to be directed at the telephonist, and it seems also that the volume of the usual criticism diminished. There may be a connection here with a gradually wider range of people, including more women, using the system. Further examination of press 
coverage and other cultural sources in the interwar years would reveal this. By this time, too, the female telephonist was being firmly mobilised as a symbol of the GPO's modernity, particularly in its post-1934 marketing and publicity following the appointment of Stephen Tallents. ${ }^{94}$ Furthermore there perhaps had been another gradual shift by the 1930s. The female telephonist had been audible and visible in popular culture for around two generations; although stereotypes remained about her chattiness and incompetence, she was a figure that the public had gradually become used to as a part of everyday life and because of the switchboard and the headset which provided instant recognition, she had also become, in some senses, an icon.

Clearly, objections to women's voices in public space remained. Kate Murphy shows how women contributors to BBC radio programmes in the late 1920s and 1930s were gradually and not without contention accepted - even if the majority of their contributions were made on topics relating to women and children - but that the first female announcer, a married woman with a child, was let go from that position after several months because of the levels of complaints about her reading the news and introducing other serious topics. As Murphy points out, broadcasters entered private homes, just as telephonists in effect did, and there were still boundaries around what could and could not be women's work and the levels of authority women could not be seen to surpass. ${ }^{95}$

It is, however, beyond the scope of this article to fully assess the ways in which the cultural understandings of the female telephonist changed or not throughout the interwar years and perhaps beyond. There is more work to do to analyse shifting or declining impressions of the female telephone operator as technology advanced and film emerged as a leading cultural medium to reinforce or rewrite perceptions of the telephonist.

\section{Conclusions}

Reactions to the female telephone operator have to be seen in the context of attitudes to, and anxieties about, new forms of employment for women, as well as the uncertainties about new technology and what it offered. The responses to the female telephonist were intertextual and soon crystallised, and even though, as we have seen, there were attempts to challenge the dominant impressions, this was never entirely possible. The examination of the depiction of female telephone operators in fiction reveals further how they had become part of daily life, 
how their presence had captured imaginations and how literature engaged with, and contributed to, some of the dominant cultural depictions of the female telephonist. More widely, whilst the evidence presented here contributes strongly to the British national history of telephony and gendered telephone operations, it is also part of a transatlantic story of the reception and development of telephony and the female telephonist.

The research presented here demonstrates that although telephone conversations relied on women's labour, this was, despite being highly evident and audible, often undervalued. Female telephonists were expected never to make mistakes, and were thus seen as the imperfect part of the machine when they did so. As the telephonist Kathleen J Furlong reminded newspaper readers in 1926 '[a]lthough we are nearly automatic, we are human'.96 As indicated, further research on the interwar years and beyond would reveal the extent to which representations of the female telephonist altered over time. Beyond this, there remain a number of important potential new avenues of research about working conditions and the woman telephonist's experience of work. These pertain, for example, to the health and safety dimensions of this work highlighted, for instance, in the 1910 report, and the extent to which the Union of Post Office Workers and other unions campaigned to ameliorate women telephonists' employment conditions. ${ }^{97}$ These would be important contributions to understanding both more about cultural representations of telephonists as well as more of the realities of their working lives in Britain in this period.

\footnotetext{
${ }^{1}$ M.S., 'To the Invisible "She"”, Daily Chronicle, December 11, 1908.

${ }^{2}$ Michele Martin, 'Hello, Central?': Gender, Technology, and Culture in the Formation of Telephone Systems, (Montreal and Kingston: McGill-Queens University Press, 1991), 50109; Jill Galvan, The Sympathetic Medium: Feminine Channeling, the Occult, and
} 
Communication Technologies, 1859-1919, (Ithaca and London: Cornell University Press, 2010), 21. See also Kenneth LiPartito, 'When Women Were Switches: Technology, Work, and Gender in the Telephone Industry, 1890-1920’'American Historical Review, 99, 4 (October 1994), 1075-1111.

${ }^{3}$ F G C Baldwin, The History of the Telephone in the United Kingdom (London: Chapman and Hall, 1925); J H Robertson, The Story of the Telephone: A History of the

Telecommunications Industry of Britain, (London: Pitman and Sons, 1947); Graeme J. Milne, 'British Business and the Telephone, 1878-1911', Business History 49, 2, (2007) 163-185;

Peter Scott, 'Still a niche communications medium: The diffusion and uses of the telephone system in interwar Britain' Business History 53, 6, (2011), 801-820; Michael Kay, 'Troublesome Telephony: how users and non-users shaped the development of early British exchange telephony' Science Museum Group Journal, [online] Spring 2015, doi: http://dx.doi.org/10.15180/150308.

${ }^{4}$ Lee Holcombe, Victorian Ladies at Work: Middle-Class Working Women in England and Wales, 1850-1914 (Newton Abbot, South Devon: David \& Charles, 1973); Gregory Anderson ed. White Blouse Revolution (Manchester: Manchester University Press, 1988); Ellen Jordan, The Women's Movement and Women's Employment in Nineteenth Century Britain, Routledge Research in Gender and History, (London and New York: Routledge, 1999). For discussions of women employed in the clerical ranks of the Civil Service in this period, see Meta Zimmeck, 'Jobs for the Girls: The Expansion of Clerical Work for Women, 1850-1914' in Unequal Opportunities: Women's Employment in England, 1800-1918 ed. Angela V John, (Oxford; New York, N.Y.: Basil Blackwell, 1986); Meta Zimmeck, 'The New Woman in the Machinery of Government: A Spanner in the Works?' in Government and Expertise in Britain, 1815-1919: Specialists, Administrators and Professionals, R. Macleod ed. (Cambridge: Cambridge University Press, 1988); Meta Zimmeck, “ "The Mysteries of the Typewriter": Technology and Gender in the British Civil Service, 18701914' in Women Workers and Technological Change in Europe in the Nineteenth and Twentieth Centuries, Gertjan de Groot and Marlon Schrover eds., (London: Taylor and Francis, 1995); Helen Glew, Gender, Rhetoric and Regulation: women's work in the Civil Service and the London County Council, 1900-55, (Manchester: Manchester University Press, 2016) 
${ }^{5}$ Martha Vicinus, Independent Women: Work and Community for Single Women, 1850-1920, (London: Virago, 1985); Erika Rappaport, Shopping for Pleasure: Women in the making of London's West End, (Princeton: Princeton University Press, 2001); Lise Shapiro Sanders, Consuming Fantasies: Labour, Leisure and the London Shopgirl, 1880-1920, (Columbus: Ohio State University Press, 2006); Katherine Mullin Working Girls: Fiction, Sexuality, and Modernity (Oxford: Oxford University Press, 2016).

${ }^{6}$ In some ways, the 'New Woman' was as much a social construction as were ideas about the telephonist. See, most recently, Gillian Sutherland, In Search of the New Woman: Middleclass women and work in Britain, 1870-1914, (Cambridge: Cambridge University Press, 2015)

${ }^{7}$ Frank Scudamore, 1871 statement on the employment of women in the Post Office, as quoted in Hilda Martindale, Women Servants of the State, (London: Allen and Unwin, 1938), 17-18; Christopher Keep, 'Blinded by the Type: Gender and information technology at the turn of the century', Nineteenth Century Contexts, 23, no.1, (2001) 149-173; Pamela Thurschwell, 'Supple Minds and Automatic Hands: Secretarial Agency in Early Twentieth Century Literature', Forum for Modern Language Studies, 37, no.2, (2001), 155-168; Mullin, Working Girls, 22-30

${ }^{8}$ For discussions on marriage bars in this period see Alison Oram, Women Teachers and Feminist Politics (Manchester: Manchester University Press, 1996); Robert Bennett,

'Gendering Cultures in Business and Labour History: Marriage Bars in Clerical Employment' in Working Out Gender: Perspectives from Labour History Margaret Walsh ed., (Aldershot, Hants: Ashgate, 1999) and Glew, Gender, Rhetoric and Regulation, 178-235

${ }^{9}$ Robertson, Story of the Telephone 22-30; 79.

${ }^{10}$ Baldwin, The History of the Telephone in the United Kingdom, 269-270; Kay,

'Troublesome Telephony'.

11 The phrase 'delicacy of touch' comes from Frank Scudamore's 1871 statement on the employment of women on telegraphy in the GPO, as quoted in Martindale, Women Servants of the State, 17-18; Keep, 'Blinded by the Type'; Thurschwell, 'Supple Minds and Automatic Hands'; Mullin, Working Girls, 22-30.

12 Martin Daunton, Royal Mail: The Post Office Since 1840 (London; Dover, N.H.: Athlone Press, 1985), 217-225; Zimmeck, 'Jobs for the Girls'; Glew, Gender, Rhetoric and Regulation. 
${ }^{13}$ For discussions of public reactions to telegraphists and typists, see, in particular, Galvan, The Sympathetic Medium and Mullin, Working Girls.

${ }^{14}$ Patrick Joyce, The State of Freedom: A Social History of the British State since 1800, (Cambridge: Cambridge University Press, 2013), 83.

15 Zimmeck, 'Jobs for the Girls'; BT Archives, POST 30/3707, File XVI, memorandum, March 13, 1901; Circular to Surveyors, no.15, July 17 1901; POST 30/4404A, Telephonists, London: Difficulty in Recruiting, letter to Leith-Ross at the Treasury, May 22, 1919.

16 POST 30/4404A, File XLIV 'Telephonists. London. Welsh Applicants’, [1928]

${ }^{17}$ Keep, 'Blinded by the Type'; Thurschwell, 'Supple Minds and Automatic Hands', Galvan, The Sympathetic Medium; Mullin, Working Girls.

${ }^{18}$ POST 30/3707 File XXI.

${ }^{19}$ Post Office Circular Instruction to Post Office Surveyors, Heads of Department \& $c$. covering the Report of the Committee of Medical Officers Appointed to Inquire into the Conditions of Working of Telephonists, cd 5976, (London: HMSO, 1911), 7.

${ }^{20}$ BT Archives, TCB661/4, Correspondence, 200-201.

${ }^{21}$ Venus Green, 'Race, Gender, and National Identity in the American and British Telephone Industries', International Review of Social History 46, (2001), 199-203

${ }^{22}$ BT Archives, TCB 2/124, File V, Personnel Department Letter, March 12, 1935. The identification of Gaines is made possible thanks to the digitisation of the GPO appointment books and the cross-referencing of her appointment number mentioned in the 1935 letter. I am very grateful to David Hay of BT Archives and Elizabeth Bruton for their work in tracking down this information.

${ }^{23}$ For further discussion on how women telephonists' youth was often commented on, see Galvan, The Sympathetic Medium, 7.

${ }^{24}$ The operation, lifespan and effects of the civil service marriage bar is discussed at length in Glew Gender, Rhetoric and Regulation, 178-235.

${ }^{25}$ BT Archives, POST 30/3446, File XV, Minutes of the nineteenth meeting of the Telephone (Transfer) Committee, 19 March 1912; TCB 661/4, Correspondence, pp.200-201; TCB 661/5 Interview with Joint Board of the Amalgamated Society of Telephone Employees and the National Telephone Staff Transfer Association, columns 1691 - 1694: 
${ }^{26}$ For a brief discussion of telephonists' promotion opportunities in the GPO, see Helen Glew 'Women's Employment in the General Post Office, 1914-1939' unpublished PhD thesis, University of London, p.25.

${ }^{27}$ Kay, 'Troublesome Telephony'.

${ }^{28}$ Keep, Blinded by the Type, p.153;

${ }^{29}$ Robertson, 59-60; Kay, 'Troublesome Telephony';

${ }^{30}$ Post Office Circular, December 8, 1908, p.563.

${ }^{31}$ Keep, 'Blinded by the Type'; Thurschwell, 'Supple Minds and Automatic Hands'; Mullin, Working Girls.

32 Joyce, The State of Freedom, 94.

${ }^{33}$ Brenda Maddox, 'Women and the Switchboard', in The Social Impact of the Telephone, ed. Ithiel de Sola Pool, (Cambridge, Mass: MIT Press, 1977), 270.

${ }^{34}$ For a discussion of these points in the US context, see Carolyn Marvin, When Old Technologies were New: Thinking about Electric Communication in the Late Nineteenth Century, (Oxford: Oxford University Press, 1988), 84.

35 See, for example, Burnley Express, October 29, 1881; Yorkshire Gazette, August 18, 1884.

${ }^{36}$ For examples of reporters touring exchanges, see Pall Mall Gazette, December 1883;

'Passing News', Herald and Lakes News, November 1, 1889.

37 The Hull Packet and East Riding Times, July 29, 1881.

${ }^{38}$ The Hampshire Advertiser, January, 1897.

39 'Men and Women as Telephonists - a question of vocal chords' Daily Mail, October 23, 1901.

40 The Pall Mall Gazette, September 9, 1898.

${ }^{41}$ See, amongst others, 'The Other Side of It; or the Telephone Operator Interviewed', Manchester Times, December 11, 1886; G Ivy Saunders, 'Ill-Paid Telephone Girls' Daily Mail, October 29, 1918. In a slightly different vein, but which served largely the same purpose, the Daily Mail featured a series of articles by G Ivy Saunders in the later part of the First World War which highlighted the demands on telephonists. See G Ivy Saunders, 'The Telephonist in War-Time. How She Does Her Bit' Daily Mail, October 7, 1916 42 Milne, 'British Business and the Telephone'; Scott, 'Still a niche communications medium'; Kay, ‘Troublesome Telephony'; Angel Calvo, 'The Shaping of urban telephone networks in Europe, 1877-1926' Urban History vol. 33, no. 3 (2006) 
${ }^{43}$ See, for example, 'No Gum for Telephone Girls', Supplement to the Manchester Courier and Lancashire General Advertiser, June 2 1888; 'Still Single', Shetland Times, March 26, 1881.

44 'The Other Side of It; or the Telephone Operator interviewed' Manchester Times,

December 11, 1886.

45 'Married by Telephone', The Evening Bulletin, (Maysville, KY), February 11, 1890;

'Married by Telephone', Bismarck Weekly Tribune, February 28, 1890; 'Married by

Telephone', Ketchum Keystone, March 8, 1890

46 'Married by Telephone', The Anaconda Standard, March 15, 1890

47 'Married by Telephone', The Anaconda Standard, March 15, 1890

48 'Married by Telephone', The North-Eastern Daily Gazette, February 24, 1890;

${ }^{49}$ Galvan, The Sympathetic Medium, 12.

${ }^{50}$ Post Office Circular, December 8, 1908, p.563. BT Archives, POST 30/1781, files XI-XII, 'Use of Standard Expressions for Telephone Operators'.

${ }^{51}$ Post Office Circular, December 8, 1908, p.563.

52 Morning Leader, December 10, 1908.

${ }^{53}$ Birmingham Evening Despatch, December 9, 1908. A similar point was made by the

Manchester Despatch, December 9, 1908. See also the cartoon and accompanying article in the Daily Mirror, December 10, 1908.

${ }^{54}$ Dundee Courier, December 9, 1908. See also the sketch that appeared in the paper the following day: Dundee Courier, December 10, 1908.

${ }^{55}$ Birmingham Daily Mail, December 9, 1908.

${ }^{56}$ Evening Standard, December 9, 1908. See also Tatler, December 16, 1908.

${ }^{57}$ Manchester Evening Chronicle, December 10, 1908. A similar point was made by 'Tel.

Of.' in a letter to The Civilian, December 26, 1908.

${ }^{58}$ M.S., 'To the Invisible "She”, Daily Chronicle, December 11, 1908.

59 Touchstone, 'A Telephone Call', Daily Mail, December 12, 1908.

${ }^{60}$ Sketch, December 16, 1908.

${ }^{61}$ Irish Times, December 10, 1908.

${ }^{62}$ Sketch, December 16, 1908.

${ }^{63}$ POST 30/1781, file XIV, letters from Miss Clark, December 22, 1908, and Miss

Goodchild, December 12, 1908.

${ }^{64}$ POST 30/1781, file XIV, list of subscriber responses to new expressions, no date [1909]. 
65 ‘A grateful man', 'Sunshine Girls', Daily Mail, January 25, 1924

${ }^{66}$ See, for example, 'Amusements in Liverpool', The Era, September 25, 1897.

${ }^{67}$ Galvan, The Sympathetic Medium, 12.

${ }^{68}$ Richard Menke, 'The Medium is the Media: Fictions of the Telephone in the 1890s'

Victorian Studies vol. 55, no.2, (Winter 2013), 212-3. For a discussion of portrayals of the telephone and telephonists in US literature of the late nineteenth and twentieth centuries, see John Brooks, 'Telephone Literature' in The Social Impact of the Telephone, ed. Ithiel de Sola Pool, 208-224.

${ }^{69}$ E.F. Benson, Dodo's Daughter, 81

70 Benson, Dodo's Daughter, 371

${ }^{71}$ Benson, Dodo's Daughter, 208

72 Virginia Woolf, Night and Day [1919], (London: Penguin, 1992), 215. I am grateful to Leigh Wilson for alerting me to this depiction.

${ }^{73}$ Woolf, Night and Day, passim.

${ }^{74}$ Askew and Askew, The Telephone Girl, 279.

75 Askew and Askew, The Telephone Girl, 286-7.

${ }^{76}$ Galvan, The Sympathetic Medium, 12.

77 Askew and Askew, The Telephone Girl, 227-8.

78 Askew and Askew, The Telephone Girl, 296.

${ }^{79}$ Galvan, The Sympathetic Medium, 11-12.

${ }^{80}$ The Weekly Standard and Express, April 30, 1898.

${ }^{81}$ The Civilian, August 5, 1911. For a discussion of the first automatic exchange, see John Liffen, 'Epsom, Britain's First Public Automatic Exchange', The International Journal for the History of Engineering \& Technology, 82, no.2 (2012), 210-232.

82 Sheila Lewenhak, Women and Trade Unions (London, and Tonbridge, Kent: Ernest Benn, 1977); Sarah Boston, Women Workers and the Trade Unions, (London: Lawrence and Wishart, 1987); Glew, Gender, Rhetoric and Regulation.

${ }^{83}$ The Civilian, August 5, 1911.

${ }^{84}$ Association Notes, 1911 ?

${ }^{85}$ BT Archives, POST 30/1153B, Government interdepartmental telephonic communication at the Treasury, File 3 [1909]. 
${ }^{86}$ Post Office Circular Instruction to Post Office Surveyors, Heads of Department \& $c$. covering the Report of the Committee of Medical Officers Appointed to Inquire into the Conditions of Working of Telephonists, 1911, 6-12.

${ }^{87}$ BT Archives, POST 30/2475 Enquiry into working conditions for telephonists part 2 [1909-1911]; POST 30/2476 Enquiry into working conditions for telephonists part 3 - end [1910-1919].

${ }^{88}$ BT Archives, POST 30/4404A, File XXV, Telephonists, London: Difficulty in Recruiting, report of Miss D H Jones, November 20, 1918

${ }^{89}$ Although telephonists sat examinations similar to those taken by candidates for other civil service roles of similar entry points and salaries, the process also included an initial personal interview to assess the suitability of the candidates voice and diction. The GPO refused the Whitley Council's suggestion. See POST 30/4404A, File XXXV, correspondence April 9, 1921 - May 31, 1921.

${ }^{90}$ See, for example, POST 30/4404A, File XXVIII

${ }^{91}$ POST 30/4404A, Telephonists, London: Difficulty in Recruiting, memo, September 21, 1919

${ }^{92}$ See, for example, 'The London Subscriber', The Telegraph and Telephone Journal, June 1915, 188; Amy Bell, 'As Others See Us’ The Telegraph and Telephone Journal, September $1915,258-260$.

${ }^{93}$ Letter from Kathleen J Furlong, Daily Mail, Tuesday $17^{\text {th }}$ August 1926 . See also The Telegraph and Telephone Journal, January 1931, where Miss L M Benson called for a 'telephone conscious community'.

${ }^{94}$ For a discussion of Tallents' appointment, see Daunton, Royal Mail, 354. See also the cover of the February 1937 Post Office Magazine, which was distributed to all GPO staff, and John Cooper's commissioned painting The International Telephone Exchange of London, completed in 1935.

${ }^{95}$ Kate Murphy, Behind the Wireless: A History of Early Women at the BBC, (Basingstoke: Palgrave Macmillan, 2016), 223-225; 241-243.

${ }^{96}$ Letter from Kathleen J Furlong, Daily Mail, August 17, 1926

97 Glew, 'Women's Employment in the General Post Office, 1914-1939' chapter 5 considers the question of representation of women in the UPW after 1918 (and its predecessors during the First World War) but there is certainly greater scope to the consider the specific campaigns by the UPW to improve women telephonists' working conditions. 